\title{
BMJ Open Knowledge and use of evidence-based medicine in daily practice by health professionals: a cross-sectional survey
}

\author{
Carmelo Lafuente-Lafuente, ${ }^{\oplus 1,2}$ Catia Leitao, ${ }^{3}$ Insaf Kilani, ${ }^{3}$ Zineb Kacher, ${ }^{3}$ \\ Cynthia Engels, ${ }^{4}$ Florence Canouï-Poitrine, ${ }^{4,5,6}$ Joël Belmin ${ }^{1,2}$
}

To cite: Lafuente-Lafuente C, Leitao C, Kilani I, et al.

Knowledge and use of evidencebased medicine in daily practice by health professionals: a crosssectional survey. BMJ Open 2019;9:e025224. doi:10.1136/ bmjopen-2018-025224

- Prepublication history and additional material for this paper are available online. To view these files, please visit the journal online (http://dx.doi. org/10.1136/bmjopen-2018025224).

Received 4 July 2018

Revised 15 January 2019

Accepted 22 January 2019

Check for updates

(C) Author(s) (or their employer(s)) 2019. Re-use permitted under CC BY-NC. No commercial re-use. See rights and permissions. Published by BMJ.

For numbered affiliations see end of article.

Correspondence to

Dr Carmelo Lafuente-Lafuente; c.lafuente@nodo3.net

\section{ABSTRACT}

Objectives Healthcare professionals are expected to firmly ground their practice in sound evidence. That implies that they know and use evidence-based medicine (EBM). In this study, our aim was to know how often health professionals actually made use of EBM in their daily practice.

Design A questionnaire survey of healthcare professionals.

Participants Healthcare professionals who attended six university postgraduate courses. 226 answered the questionnaire (144 physicians, 64 nurses and 24 pharmacists; response rate $63.3 \%$ ).

Setting $56.5 \%$ of respondents worked in hospitals (mostly non-teaching), $25.0 \%$ in nursing homes and $10.2 \%$ in primary care. All participants were French-speaking and lived in France or Switzerland.

Measures Declared degree of knowledge and use of EBM, use of EBM-related information sources.

Results Overall, $14.2 \%$ of respondents declared to use EBM regularly in their daily practice and $15.6 \%$ declared to use EBM only occasionally. The remaining respondents declared they: knew about EBM but did not use it (33.1\%), had just heard about EBM $(31.9 \%)$ or did not know what EBM is (4.0\%). Concerning the use of EBM-related information sources, $83.4 \%$ declared to use at least monthly (or more often) clinical guidelines, $47.1 \%$ PubMed, $21.3 \%$ the Cochrane Library and $6.4 \%$ other medical databases. Fewer pharmacists $(12 \%)$ declared to use EBM in their practice than nurses $(22 \%)$ or doctors (36\%). No difference appeared when analysed by gender, work setting or years after graduation. The most frequent obstacles perceived for the practice of EBM were: lack of general knowledge about EBM, lack of skills for critical appraisal and lack of time.

Conclusions Only a minority of health professionalswith differences between physicians, nurses and pharmacists-declare to regularly use EBM in their professional practice. A larger proportion appears to be interested in EBM but seems to be deterred by their lack of knowledge, skills and personal time.

\section{INTRODUCTION}

In the early 90s, a group of clinicians and clinical epidemiologists introduced evidencebased medicine (EBM). ${ }^{1}$ The key idea was to refocus medical practice on evidence

\section{Strengths and limitations of this study}

- We surveyed a convenience sample, not a random, population-based sample, so caution is needed in generalising the findings to the overall population of health professionals.

- This study has the limits of any declarative survey, especially a risk of social desirability bias (declaring better practices than actually conducted because expected to do so).

- As strengths, this survey cumulated a good number of respondents and included nurses and pharmacist as well as doctors.

- Besides, respondents came from diverse specialties and practice settings, thus providing a better idea of the overall knowledge and use of evidence-based medicine in healthcare than other studies.

from high-quality clinical trials, instead of more traditional sources of knowledge, like experts' opinion, the understanding of pathophysiology or academic authority. ${ }^{12}$ The EBM movement has greatly influenced medical teaching, lead to the formation of the Cochrane Collaboration to summarise evidence from clinical trials, and set methodological and publication standards for clinical research, as well as for developing clinical practice guidelines. ${ }^{3-7}$

Furthermore, one top priority of EBM is the care of individual patients. ${ }^{6-8}$ Indeed, a classical definition of EBM is 'the integration of the best available evidence with clinical expertise and patient values and preferences'. ${ }^{2}$ EBM was originally intended to be employed by individual professionals in their usual practice. ${ }^{2}$ The objective was to provide the health practitioner with the ability to critically assessing evidence from research and adapting it to a particular patient and setting. Today, healthcare professionals are expected to base their practice in strong evidence. That means they should have at least basic skills for retrieving, assessing and integrating evidence. It is not clear, however, to which 
extent clinicians have been able to integrate EBM for decision-making in their daily practice.

Several surveys have assessed the attitudes, perception or knowledge about EBM of physicians in different countries. ${ }^{9-17}$ We did not find any published systematic review on this topic. The vast majority of surveys have been conducted either in general practice or in diverse medical specialties at the hospital. The majority of those studies have found that only a minority of professionals show good knowledge and consistent use of EBM. However, the figures varied widely between studies, most of those surveys included only physicians, and few of them asked participants how often they actually employed EBM in their practice for solving clinical problems or decision-making with patients.

In this work, our aim was to assess the frequency of use of EBM in daily practice by health practitioners of diverse professions and practice settings. A secondary aim was to identify obstacles to the practice of EBM. To this end, we conducted a questionnaire survey on a convenience sample of doctors, pharmacists and nurses who attended several university postgraduate courses.

\section{METHODS}

\section{Study design}

A cross-sectional survey.

\section{Participants and sampling}

This was a non-random, convenience sampling composed of physicians, nurses and pharmacists who attended in 2015 and 2016 six postgraduate university courses at Paris, France. The courses dealt with various aspects of the management of old patients (therapeutics, drugs use in older patients, ageing and general care of elderly patients).

\section{Questionnaire}

The questionnaire, self-completed, was composed of five closed, multiple-choice questions. A set of short questions about basic demographic characteristics were followed by questions about: (a) how much the respondent felt she knew EBM and used it in her daily practice; (b) how much she felt she knew and used the Cochrane Library or any Cochrane Collaboration material; (c) how often she employed various EBM-related information sources in her practice; and (d) what obstacles, if any, the respondent had encountered for practising EBM.

A preliminary version of the questionnaire was developed by two of the authors (CLL and CL) trying to respect as much as possible recognised best practices. ${ }^{18}$ The questionnaire was then independently reviewed by two others authors (ZK and IK) and tested in a small sample of 12 physicians and nurses, who were asked to answer the questionnaire and give feedback on it. We took notes on the time people took to complete it, how they reacted to the specific questions and whether any question needed to be explained. We recorded any critic and suggestion.
Any suggestion made by two or more participants was automatically integrated into the questionnaire. The investigators (CLL, CL and ZK) discussed those suggestions made by single participants and included them if consensus. All questions were partly rephrased. There was no formal assessment of its validity and reliability. The final questionnaire employed in the survey is provided in the online Supplementary file.

\section{Statistics}

We described the answers obtained in the survey using numbers (proportions). Missing data (unanswered questions) were removed and the total number of respondents was always specified. We assessed whether several variables (gender, profession, specialty, years of work after graduation and work setting) were significantly associated with the declared degree of knowledge and use of EBM using univariate two-sided $\mathrm{X}^{2}$ test and multivariate multinomial logistic regression. Likelihood ratio $X^{2}$ was employed when the assumptions of the $\mathrm{X}^{2}$ test were not met. Categorisation of variables is described in the online supplementary file table S1). The threshold for significance was set at 0.05 . No sample size was pre-specified or calculated; we simply tried to obtain as many responses as possible during the study period. STATA software V.13.1 SE was employed for data management and statistics.

\section{Ethics}

The questionnaire was proposed to health professionals with no obligation to answer it. Respondents were informed of the study's purpose, content and duration, as well as the fact that they did not have to answer all the questions and could stop participating in the study at any point. The questionnaire was anonymous, no identity data were recorded and it was impossible to link respondents' names to their surveys. Under French regulations at the time the study was conducted, an anonymous survey conducted on health professionals—not in patients—did not need approval by an ethics committee.

\section{Patient involvement}

Patients were not involved in the design or the conduct of this study.

\section{RESULTS}

The survey was proposed to 357 professional, of whom $226(63.3 \%)$ returned a filled questionnaire. The characteristics of respondents are presented in table 1.

There were more physicians $(63.7 \%)$ than nurses $(23.9 \%)$ or pharmacists $(10.6 \%)$. Most physicians were general practitioners or geriatricians. The majority of respondents worked in hospitals (mostly non-teaching) or nursing homes. About half $(55.5 \%)$ of respondents have been working for $<10$ years after their graduation.

\section{EBM knowledge and use in professional practice}

Overall, $45.6 \%$ of respondents stated that they did not directly use EBM in their professional practice, and $35.9 \%$ 
Table 1 Characteristics of respondents

\begin{tabular}{|c|c|}
\hline Variable & $\begin{array}{l}\text { No. }(\%) \\
n=226\end{array}$ \\
\hline Women & $149(65.9)$ \\
\hline Years of work after graduation & $(n=183)$ \\
\hline $0-10$ & $101(55.5)$ \\
\hline 10-20 & $46(25.1)$ \\
\hline$>20$ & $36(19.7)$ \\
\hline Median (IQR) & $10(4-20)$ \\
\hline \multicolumn{2}{|l|}{ Profession } \\
\hline Physician & $144(63.7)$ \\
\hline General practice/family medicine & $79(35.0)$ \\
\hline Geriatrics & $60(26.5)$ \\
\hline Other specialties & $5(2.2)$ \\
\hline Nurse & $54(23.9)$ \\
\hline Pharmacist & $24(10.6)$ \\
\hline Hospital pharmacy & $16(7.1)$ \\
\hline Community pharmacy & $5(2.2)$ \\
\hline Pharmaceutical industry & $3(1.3)$ \\
\hline Other or non-stated & $4(1.8)$ \\
\hline Work setting & $(n=216)$ \\
\hline Non-teaching hospital & $89(41.2)$ \\
\hline Nursing home & $54(25.0)$ \\
\hline Teaching hospital & $33(15.3)$ \\
\hline Community (general practice) & $22(10.2)$ \\
\hline $\begin{array}{l}\text { Others (social insurance, health system } \\
\text { administration) }\end{array}$ & $9(4.2)$ \\
\hline Currently not in practice & $9(4.2)$ \\
\hline
\end{tabular}

reported that they could not give a definition of EBM (table 2). An additional $22.1 \%$ of respondents affirmed to read sources of professional information labelled as 'EBM' but made no other use of EBM. Conversely, 28.8\% of participants stated that they directly employed EBM in their practice, either occasionally or regularly, for decision-making.

The declared degree of knowledge and use of EBM differed between professions (figure 1). Fewer pharmacists affirmed to practice EBM, either occasionally or regularly, than nurses ( $12 \%$ vs $22 \%$ respectively, difference $9.7 \%, 95 \%$ CI $0.7 \%$ to $26.9 \%, p=0.01$ ) or than physicians (12\% vs $36 \%$, difference $23.5 \%, 95 \%$ CI $8 \%$ to $39 \%$, $\mathrm{p}=0.005)$. Fewer nurses than physicians declared to practice EBM regularly, but a similar proportion said they used EBM occasionally or that they employed EBM-related resources (overall, $\mathrm{p}=0.23$ for the comparison nurses vs physicians).

There was no difference in the degree of knowledge and use of EBM when analysed by gender $(p=0.23)$, work setting $(p=0.31)$, medical specialty $(p=0.79)$ or years of work after graduation $(p=0.39)$. In a multivariate logistic regression model combining these variables,
Table 2 Frequency of use of EBM in daily practice and perceived obstacles

\begin{tabular}{|c|c|}
\hline Answers & $\begin{array}{l}\text { Respondents } \\
\text { no. }(\%) \\
n=226\end{array}$ \\
\hline \multicolumn{2}{|l|}{ Knowledge and use of EBM } \\
\hline Do not know what EBM is, do not use it & $9(4.0)$ \\
\hline Just heard about EBM, do not use it & $72(31.9)$ \\
\hline Can define EBM but do not use it & $22(9.7)$ \\
\hline $\begin{array}{l}\text { Of whom: do not agree with EBM } \\
\text { approach }\end{array}$ & $7(3.1)$ \\
\hline $\begin{array}{l}\text { Do not use EBM directly but employ EBM- } \\
\text { labelled resources }\end{array}$ & $50(22.1)$ \\
\hline $\begin{array}{l}\text { Use EBM directly in her practice, } \\
\text { occasionally }\end{array}$ & $34(15.1)$ \\
\hline Use EBM directly in her practice, regularly & $31(13.7)$ \\
\hline Did not answered & $8(3.6)$ \\
\hline \multicolumn{2}{|l|}{ Obstacles perceived for the practice of EBM } \\
\hline Lack of general knowledge on EBM & 87 (38.5) \\
\hline Lack of time & $59(26.1)$ \\
\hline $\begin{array}{l}\text { Lack of skills for critical appraisal of } \\
\text { studies }\end{array}$ & $49(21.7)$ \\
\hline $\begin{array}{l}\text { Availability and access to information } \\
\text { sources }\end{array}$ & $42(18.6)$ \\
\hline No obstacle found & $21(9.3)$ \\
\hline Others & $3(1.3)$ \\
\hline Did not answered & $5(2.2)$ \\
\hline
\end{tabular}

EBM, evidence-based medicine.

the profession was the only variable significantly associated with the declared degree of knowledge and use of EBM (online supplementary data figure S1).

\section{Frequency of use of specific evidence-based information resources}

Clinical guidelines were the information source most frequently employed by the professionals answering to this survey (table 3). Again, some differences appeared between professions: fewer nurses $(68.5 \%, \mathrm{p}=0.009)$ than physicians $(89.2 \%)$ or pharmacists $(87.5 \%)$ declared to use guidelines at least monthly or more often.

Guidelines were followed by the use of PubMed searches, which $47.1 \%$ of respondents affirmed to search at least monthly, but only $13.4 \%$ did it weekly. The Cochrane Library was less frequently used: $21.3 \%$ declared to consult it at least monthly (3.2\% weekly), less than half the frequency of use of PubMed. Finally, a vast majority of respondents $(93.6 \%-98.3 \%)$ rarely or never used the other evidence sources we listed in the questionnaire.

\section{Obstacles perceived for the practice of EBM}

Lack of knowledge of the EBM process and lack of the skills required were the main obstacles found by the participants in their personal practice: one or the other 


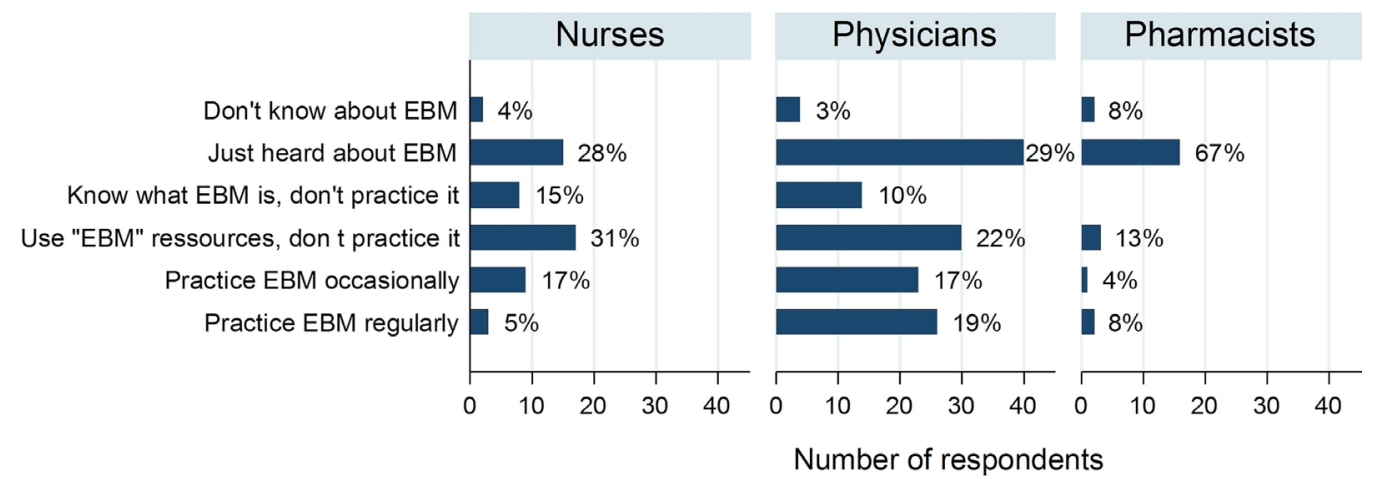

Figure 1 Frequency of use of EBM by profession. EBM, evidence-based medicine.

was mentioned by $60.2 \%$ of them. Lack of time and difficulties to access information sources were also obstacles respondents frequently reported (table 2 ).

\section{DISCUSSION}

The responses to this survey show that few professionals regularly use EBM in their daily practice and that many feel they lack adequate skills to perform by themselves the core EBM process of searching for, appraising and applying evidence. On the other hand, a larger proportion of respondents declared that they either employed EBM but only occasionally, or, while not directly employing EBM, they tried to use resources labelled as EBM-based. Pooled, those who employed EBM-more or less frequently-or used EBM-labelled resources made $51 \%$ of all participants in the survey. This is roughly consistent with the proportions of participants $(47.2 \%)$ who declared to search PubMed at least monthly or more often. Overall, these findings suggest that health professionals have a real interest in employing EBM in some way, even if few actually apply EBM directly on a regular basis.
Concerning professional information sources, a large majority of professionals in this survey consulted mainly guidelines from official organisations and specialty societies, much more than they searched PubMed, the Cochrane Library or any other bibliographical database. This is logical, though, because conducting a good, comprehensive search for primary evidence (ie, for single research studies, like randomised controlled trials or observational studies, that investigate each an aspect of clinical interest) requires some skills and is time-consuming. Moreover, precisely, the lack of skills and time, together with poor general knowledge of EBM, were perceived in this survey as the most frequent obstacles encountered for practising EBM. These obstacles should be addressed in order to further spread the knowledge and implementation of EBM.

\section{Strengths and limitations}

In this work, we took advantage of the attendance of various types of health professionals, doctors, nurses and pharmacists, to several university diplomas, two professional seminars and one Master carried in our university, to propose them to participate in the survey. However, this

Table 3 Frequency of use of several evidence-based information resources

\begin{tabular}{|c|c|c|c|c|c|}
\hline & $\begin{array}{l}\text { Rarely or never } \\
\text { n (\%) }\end{array}$ & $\begin{array}{l}1 \text { to } 3 \text { times a } \\
\text { month } \\
\text { n (\%) }\end{array}$ & $\begin{array}{l}1 \text { to } 3 \text { times a } \\
\text { week } \\
\text { n }(\%)\end{array}$ & $\begin{array}{l}\text { Almost every day } \\
\text { n (\%) }\end{array}$ & $\begin{array}{l}\text { Total number } \\
\text { of respondents }\end{array}$ \\
\hline PubMed (Medline) & $102(52.9)$ & $65(33.7)$ & 25 (12.9) & $1(0.5)$ & 193 \\
\hline Cochrane Library & $148(78.7)$ & $34(18.1)$ & $6(3.2)$ & 0 & 188 \\
\hline DARE & $113(97.4)$ & $3(2.6)$ & 0 & 0 & 116 \\
\hline TRIP, SUMsearch or ACCESSSS & $168(98.3)$ & $3(1.7)$ & 0 & 0 & 171 \\
\hline
\end{tabular}

HAS, French Haute Autorité de Santé. https://www.has-sante.fr.

NICE, UK National Institute for Clinical Excellence. https://www.nice.org.uk/.

CINAHL, Cumulative Index to Nursing and Allied Health Literature. https://www.ebsco.com/.

DARE, Database of Abstracts of Reviews on Effectiveness. https://www.crd.york.ac.uk/CRDWeb/.

TRIP, Turning Research Into Practice database. https://www.tripdatabase.com.

SUMsearch, A federated or meta-search engine. http://sumsearch.org/.

ACCESSSS, ACCESSSS Federated Search. https://plus.mcmaster.ca/ACCESSSS/. 
did not constitute a random sample of all health professionals. In particular, as courses were about the care of elderly patients, professionals working in geriatrics were certainly over-represented. Besides, the number of participating nurses and pharmacists was relatively low. Consequently, caution is needed in generalising our findings to the overall population of health professionals.

This study has the limits of any declarative survey, too. There is always a risk of social desirability biassing the answers. For instance, as health professionals are supposed to know and follow official guidelines, they may have declared a greater frequency of its use than actually made.

As strengths, this survey cumulated a good number of respondents, coming from diverse practice settings, different specialties and various healthcare professions, thus providing a better idea of the overall knowledge and use of EBM in healthcare than many previous studies, frequently focused in a specific profession and a particular setting.

\section{Comparison with previously published studies}

Previous studies included nurses and physicians working in various specialties-mainly general practice, family medicine and general internal medicine-and in various settings-mainly primary care and teaching hospitals. ${ }^{9-17}$ Direct comparisons are not possible, because the questionnaires used in each study are very different, but the results from most surveys are similar to ours and are globally coincident; the proportion of professionals having a good knowledge of EBM, having good critical appraisal skills or personally implementing EBM in their practice is consistently low. The same obstacles to more extensive use of EBM come again and again in virtually all studies: lack of time, lack of required skills and limited access to sources of evidence. It is very striking that it does not seem to exist any substantial progress along time with respect to the first surveys conducted in the $90 \mathrm{~s}$, neither in the degree of knowledge of EBM nor in the nature of the obstacles reported. It is also striking that there are no obvious differences between countries, for instance, between English-speaking and non-English-speaking countries.

Our study shows, however, that important differences may exist between the different professionals involved in healthcare. Dissimilarities in EBM (or evidence-based practice) teaching can explain them: in our country, the syllabus of physicians integrates more EBM teaching time than those of nurses and pharmacists, and only physicians have courses on critical appraisal of biomedical articles. These dissimilarities between professions are particularly relevant in modern medicine, where the collaboration between physicians, nurses and other practitioners is increasingly intense and important. Ideally, they should be reduced.

Other difference with previous studies is that in this survey, no difference was found between professionals working at the hospital and elsewhere, or between professionals with fewer and more years of practice (ie, younger and older professionals).

\section{Implications for practice}

High use of guidelines combined with low use of primary evidence suggests that many professionals probably do not (or are unable to) verify independently, by their own means, the validity of what is stated in guidelines, or otherwise what is presented to them as 'EBM-based'. In this survey, for instance, $22 \%$ of respondents declared to seek EBM-labelled resources but not to use EBM by themselves. A large majority consulted clinical guidelines, more or less frequently, but only $21 \%$ consulted with some frequency the Cochrane Library.

That means that probably many health professionals are dependent on others to search for, assess, synthetise and interpret available evidence. They have become final consumers of preprocessed, prepackaged evidence. Many experts, in fact, have advocated for generalising the use of evidence synthesis and summaries as the only way to make evidence accessible to busy clinicians who do not have the time or the skills to carry out the steps of 'traditional' EBM. ${ }^{19}{ }^{20}$ Others, however, have underlined the risks and potential pitfalls of excessive reliance on clinical guidelines, not always up to date and regularly suspected of being biased by poor methodology and conflict of interests. ${ }^{21-24}$ Healthcare professionals should know, at the very least, how to assess the extent to which a guideline is actually evidence-based. In addition, they would need to know how to critically read selected key studies if they wanted to discuss specific, new or controversial recommendations, or be able to navigate the contemporary overload of medical information of very diverse quality, what Ioannidis et al have called 'the medical misinformation mess'. ${ }^{25}$

\section{CONCLUSIONS}

In conclusion, a minority of health professionals-with some differences between physicians, nurses and pharmacists-declared to regularly use EBM in their professional practice or regularly consult sources of primary evidence, like PubMed and the Cochrane Library. A larger proportion of professionals are aware of the existence and the basic ideas of EBM and appear to look for implementing EBM in some way in their practice, consulting EBM-labelled resources and clinical guidelines. However, it seems that many of them are deterred by their lack of knowledge about EBM, lack of required skills and lack of personal time.

These results suggest that a majority of health professionals are currently dependent on external 'authorities' for searching, assessing and synthetising available evidence for them. Changing this situation to further promote direct use of EBM in daily practice-or, at least, the ability to critically read guidelines and other evidence synthesis-would require to help health professionals to acquire basic skills in EBM and to allow them time 
available for practising EBM. More research is needed to find effective ways of achieving those objectives.

\section{Author affiliations}

${ }^{1}$ Gériatrie à orientation Cardiologique et Neurologique, APHP, Hôpitaux univesitaires Pitié-Salpêtrière-Charles Foix, Ivry-sur-Seine, France

${ }^{2}$ Geriatrics Deparment, Sorbonne Université, Paris, France

${ }^{3}$ Plateforme de recherche clinique, APHP, Hôpitaux universitaires Pitié-SalpêtrièreCharles Foix, Ivry-sur-Seine, France

${ }^{4}$ IMRB, A-TVB DHU, CEpiA EA 4393 (Clinical Epidemiology and Ageing Unit), Institut d'Ergothérapie, Université Paris Est Créteil (UPEC), Créteil, France

${ }^{5}$ Public Health Department, Henri Mondor Hospital, Assistance Publique - Hopitaux de Paris, Paris, France

${ }^{6}$ IMRB, A-TVB DHU, CEpiA EA 4393 (Clinical Epidemiology and Ageing Unit), Université Paris Est Créteil (UPEC), Créteil, France

Acknowledgements The authors acknowledge Dr Maria Pociumban and Ms Marie-Paule Razanadraibe for helping to extract data from paper questionnaires.

Contributors CL-L: conception and design of the study, acquisition, analysis and interpretation of data, drafting and critical revision of the manuscript and statistical analysis. CL: design of the study, acquisition, analysis and interpretation of data, critical revision of the manuscript and statistical analysis. IK: acquisition and analysis of data, drafting of the manuscript, administrative and technical support. ZK: acquisition and analysis of data, revision of the manuscript, statistical analysis and technical support. CE: analysis and interpretation of data, critical revision of the manuscript and supervision. FC-P: design of the study, analysis and interpretation of data, drafting and critical revision of the manuscript. JB: conception of the study, interpretation of data, critical revision of the manuscript, supervision and obtaining funding.

Funding This work was supported by Assistance Publique - Hôpitaux de Paris and Sorbonne Université (no specific grants numbers).

Competing interests None declared.

Patient consent for publication Not required.

Provenance and peer review Not commissioned; externally peer reviewed.

Data sharing statement The survey questionnaire (in French) and full dataset are available from the Open Science Framework, DOI: 10.17605/OSF.IO/ZJPDV

Open access This is an open access article distributed in accordance with the Creative Commons Attribution Non Commercial (CC BY-NC 4.0) license, which permits others to distribute, remix, adapt, build upon this work non-commercially, and license their derivative works on different terms, provided the original work is properly cited, appropriate credit is given, any changes made indicated, and the use is non-commercial. See: http://creativecommons.org/licenses/by-nc/4.0/.

\section{REFERENCES}

1. Evidence-Based Medicine Working Group. Evidence-based medicine. A new approach to teaching the practice of medicine. JAMA 1992;268:2420-5.

2. Sackett DL, Rosenberg WM, Gray JA, et al. Evidence based medicine: what it is and what it isn't. BMJ 1996;312:71-2.

3. Simera I, Moher D, Hirst A, et al. Transparent and accurate reporting increases reliability, utility, and impact of your research: reporting guidelines and the EQUATOR Network. BMC Med 2010;8:24.
4. Hill J, Bullock I, Alderson P. A summary of the methods that the National Clinical Guideline Centre uses to produce clinical guidelines for the National Institute for Health and Clinical Excellence. Ann Intern Med 2011;154:752-7.

5. Horsley T, Hyde C, Santesso N, et al. Teaching critical appraisal skills in healthcare settings. Cochrane Database Syst Rev 2011:CD001270.

6. Greenhalgh T, Howick J, Maskrey N. Evidence Based Medicine Renaissance Group. Evidence based medicine: a movement in crisis? BMJ 2014;348:g3725.

7. Djulbegovic B, Guyatt GH. Progress in evidence-based medicine: a quarter century on. Lancet 2017;390:415-23.

8. Smith R, Rennie D. Evidence-based medicine--an oral history. JAMA 2014;311:365-7.

9. McColl A, Smith H, White P, et al. General practitioner's perceptions of the route to evidence based medicine: a questionnaire survey. BMJ 1998;316:361-5.

10. Al-Ansary LA, Khoja TA. The place of evidence-based medicine among primary health care physicians in Riyadh region, Saudi Arabia. Fam Pract 2002;19:537-42.

11. Oliveri RS, Gluud C, Wille-Jørgensen PA. Hospital doctors' selfrated skills in and use of evidence-based medicine - a questionnaire survey. J Eval Clin Pract 2004;10:219-26.

12. Ahmadi-Abhari S, Soltani A, Hosseinpanah F. Knowledge and attitudes of trainee physicians regarding evidence-based medicine: a questionnaire survey in Tehran, Iran. J Eval Clin Pract 2008;14:775-9.

13. Heselmans A, Donceel P, Aertgeerts $B$, et al. The attitude of Belgian social insurance physicians towards evidence-based practice and clinical practice guidelines. BMC Fam Pract 2009;10:64.

14. Ulvenes LV, Aasland O, Nylenna M, et al. Norwegian physicians' knowledge of and opinions about evidence-based medicine: crosssectional study. PLoS One 2009;4:e7828

15. Aguirre-Raya KA, Castilla-Peón MF, Barajas-Nava LA, et al. Self-perception and knowledge of evidence based medicine by physicians. BMC Med Educ 2016;16:166.

16. Dalheim A, Harthug S, Nilsen RM, et al. Factors influencing the development of evidence-based practice among nurses: a self-report survey. BMC Health Serv Res 2012;12:367.

17. Boström AM, Sommerfeld DK, Stenhols AW, et al. Capability beliefs on, and use of evidence-based practice among four health professional and student groups in geriatric care: A cross sectional study. PLoS One 2018;13:e0192017.

18. McColl E, Jacoby A, Thomas L, et al. Design and use of questionnaires: a review of best practice applicable to surveys of health service staff and patients. Health Technol Assess 2001;5:1-256.

19. Mellis C. Evidence-based medicine: what has happened in the past 50 years? J Paediatr Child Health 2015;51:65-8.

20. Haynes RB. Of studies, syntheses, synopses, summaries, and systems: the " $5 \mathrm{~S}$ " evolution of information services for evidencebased healthcare decisions. Evid Based Med 2006;11:162-4.

21. Kung J, Miller RR, Mackowiak PA. Failure of clinical practice guidelines to meet institute of medicine standards: Two more decades of little, if any, progress. Arch Intern Med 2012;172:1628-33.

22. Tinetti ME, Bogardus ST, Agostini JV. Potential pitfalls of diseasespecific guidelines for patients with multiple conditions. $N$ Engl J Med 2004;351:2870-4.

23. Lenzer J. Why we can't trust clinical guidelines. BMJ 2013;346:f3830.

24. Feuerstein JD, Akbari M, Gifford AE, et al. Systematic analysis underlying the quality of the scientific evidence and conflicts of interest in interventional medicine subspecialty guidelines. Mayo Clin Proc 2014;89:16-24.

25. Ioannidis JPA, Stuart ME, Brownlee S, et al. How to survive the medical misinformation mess. Eur J Clin Invest 2017;47:795-802. 